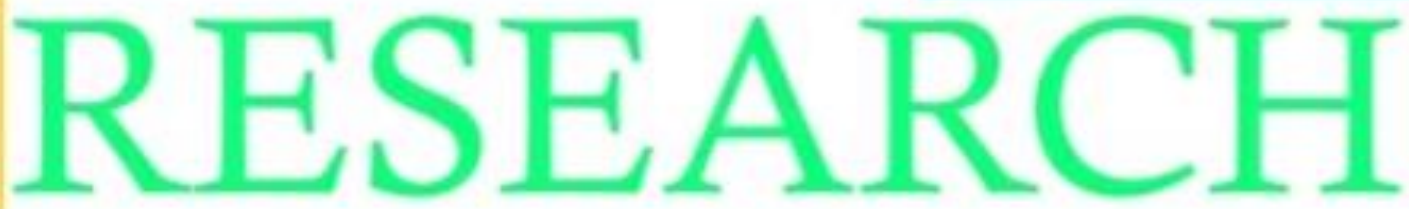

VOLUME 2 NOMOR 1 MARET 2019

IFMBABAN PURHIKASHILMIAH

- IMPLEMENTATION OF THE FLUX CORED ARC WELDING METHOD PROCEDURE IN THE MANUFACTURING WORLD

- RACHMASARI PRAMITA WARDHANI, S.T, M.M.

- IR.RISSETRIDHARMA SIMANUUNTAK, MM, ERWIN GUSTIANTA, S.T

- KELUARGA DAN RUMAH TANGgA SUATU KAJIAN ANTROPOLOGIS

DRS.. H. ANDI ARFIN, M.Si

- PENGARUH PELATIHAN TERHADAP KINERJA KARYAWAN PADA PT.BJ.SERVICE INDONESIA BALIKPAPAN

BAMBANG SUGIONO, S.E, M.M

- PENJUALAN ALAT PEMADAM API MERK GUNNEBO PADA PT. INDOLOK BAKTI UTAMA CABANG BALIKPAPAN

0 BAMBANG SUGIONO, S.E, M.M

- SISTEM PEMILIHAN UMUM UNTUK MEWUJUDKAN INTERGRITAS DPRD MENUJU PEMERINTAHAN YANG BAIK

0 INDRIATI, S.H.,M.Kn

- PENGAWASAN PENDAFTARAN HAK ATAS TANAH TELAH SESUAI DENGAN PRINSIP.PRINSIP "GOOD GOVERNANCE"

0 INDRIATI, S.H.,M.Kn

- AKIBAT HUKUM PENAHANAN UAZAH ASLI MILIK KARYAWAN YANG DILAKUKAN OLEH PERUSAHAAN

$\checkmark$ OKTA NOFIA SARI, S.H., M.H.

- UPAYA PENINGKATAN PRESTASI BELAJAR MATEMATIKA DENGAN METODE STUDENT TEAM ACHIEVEMENT DIVISION (STAD)

- (Penelitian Tindakan Kelas Pokok Bahasan Vektor di Kelas X MIPA 4 SMA Negeri 6 Balikpapan)

- SITI NORHIDAYAH, S.Pd., M.SC, JENNY RAHAYU, S.Pd

- ANALISIS PERUBAHAN JARAK BLOK ANGKUR JEMBATAN GANTUNG TERHADAP GAYA YANG TERJADI

- ACO WAHYUDI EFENDI, SITI NORHIDAYAH

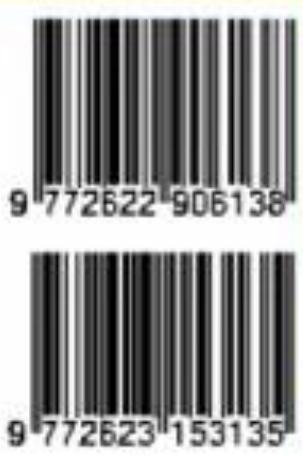

RESEARCH LEMBARAN PUBLIKASI ILMIAH UNIVERSITAS TRIDHARMA

\begin{tabular}{l|l|l|l} 
VOL.2 & NO.1 & MARET & TAHUN 2019 \\
\hline
\end{tabular}




\title{
ANALISIS PERUBAHAN JARAK BLOK ANGKUR JEMBATAN GANTUNG TERHADAP GAYA YANG TERJADI
}

\author{
Aco Wahyudi Efendi1 Siti Norhidayah ${ }^{2}$ \\ ${ }^{1}$ Program Studi Teknik Sipil, Fakultas Teknik UNTRI, Balikpapan ${ }^{2}$ Program Studi \\ Pendidikan Matematika, FKIP UNTRI, Balikpapan \\ Email: awe99struc@gmail.com¹, sn.hidayah2005@gmail.com²
}

\begin{abstract}
ABSTRAK
Sebagaimana diketahui bersama bahwa keberadaan jalan dan jembatan menjadi kunci dari perkembangan suatu wilayah atau kota. Pada jembatan gantung Tiong Ohang dilakukan perubahan jarak dari blok angkur jembatan mengikuti kondisi exiting yang terbatas, pada perubahan tersebut terjadi perubahan perilaku momen dan gaya, di mana momen setelah dilakukan pemendekan jarak blok angkur mengalami penurunan nilai momen 4,55\% dan menagalami kenaikan nilai gaya axial sebesar $19,86 \%$.
\end{abstract}

Kata Kunci :Jembatan Gantung, Momen, Axial.

\section{ABSTRACT}

As is known together, the existence of roads and bridges is the key to the development of a region or city. On the Tiong Ohang suspension bridge, the distance changes from the bridge anchor block are followed by limited exiting conditions, the changes in moment and force behavior occur, where the moment after shortening the distance of the anchor block decreases the moment value of $4.55 \%$ and experiences an increase in force value axial is $19.86 \%$.

Keyword : Suspension Bridge, Moments, Axial. 


\section{PENDAHULUN}

Sebagaimana diketahui bersama bahwa keberadaan jalan dan jembatan menjadi kunci dari perkembangan suatu wilayah atau kota. Keberadaan jalan dan jembatan akhirnya diklasifikasikan berdasarkan hirarki sebagaimana tingkatan fungsi dan pelayanan sifat jalan tersebut. Kota- kota akan selalu mempunyai jalan yang menghubungkan antara kota satu dengan kota lain yang terdekat secara administrasi. Jalan nasional umumnya merupakan jalan utama yang menghubungkan antara kota satu dengan kota lainnya serta menghubungkan antar wilayah propinsi dengan propinsi lain. Sedangkan jalan nasional umumnya menghubungkan antar wilayah kecamatan dengan kecamatan yang lainnya.

Fungsi jalan utama antara lain bertujuan untuk memperlancar pergerakan arus manusia dan barang sehingga dapat mendukung aktivitas ekonomi secara nasional. Dengan demikian, maka keberadaan jalan nasional seharusnya hambatan-hambatan yang terjadi sangat minimal. Hal tersebut mengartikan bahwa pada jalan nasional persimpangan-persimpangan yang terjadi seharusnya diminimalkan, mengingat bukaan atau persimpangan jalan nasional dengan jalan lain akan dapat menimbulkan hambatan arus lalu lintas pada jalan tersebut. Oleh karenanya pada jalan nasional haruslah dilakukan penataan dan pengawasan serta pengendalian terhadap perkembangan suatu wilayah dalam suatu kota dalam rangka mengantisipasi perkembangan kegiatan dan aktivitas masyarakat.

Kementerian Pekerjaaan Umum dan Perumahan Rakyat P2JN Kalimantan Timur berwewenang dan bertanggung jawab dalam Pembinaan sarana transportasi Jalan darat baik yang berstatus Nasional, Melalui sumber APBN Tahun Anggaran 2017 bermaksud untuk melaksanakan pekerjaan Perencanaan Teknis di Wilayah Provinsi Kalimantan Timur untuk Peningkatan Jalan, Penggantian Jembatan, rehabilitasi/Pemeliharaan Jalan/Jembatan yang akan dilaksanakan oleh penyedia pekerjaan konstruksi.

Jembatan gantung Tiong Ohang adalah jembatan gantung yang ada di salah satu kampung di kecamatan Long Apari, Kabupaten Mahakam Ulu, Provinsi Kalimantan Timur, Indonesia. Pada posisi jembatan terjadi perubahan jarak blok angkur menyesuaikan kondisi existing yang terbatas.

\section{METODE PENELITIAN}

\subsection{Tinjauan Pustaka}

Perencanaan struktur adalah kombinasi seni dan ilmu pengetahuan yang menggabungkan intuisi para ahli struktur mengenai perilaku struktur dengan pengetahuan prinsip-prinsip statika, dinamika, mekanika bahan, dan analisis struktur, untuk menghasilkan struktur yang aman dan ekonomis 
selama masa layannya. Struktur optimum dicirikan dengan biaya minimum, bobot minimum, periode konstruksi minimum, kebutuhan tenaga kerja minimum, biaya manufaktur minimum, dan manfaat maksimum pada saat layan (Mangkoesoebroto, 2007). Baja adalah suatu jenis bahan bangunan yang berdasarkan pertimbangan ekonomi, sifat, dan kekuatannya, cocok untuk pemikul beban. Oleh karena itu baja banyak dipakai sebagai bahan struktur, misalnya untuk rangka utama bangunan bertingkat sebagai kolom dan balok, sistem penyangga atap dengan bentangan panjang seperti gedung olahraga, hanggar, menara antena, jembatan, penahan tanah, fondasi tiang pancang, bangunan pelabuhan, struktur lepas pantai, dinding perkuatan pada reklamasi pantai, tangki-tangki minyak, pipa penyaluran minyak, air, atau gas. Pada Grafik 2.1 di bawah ini menerangkan hubungan antara tegangan dan regangan yang terjadi pada baja.

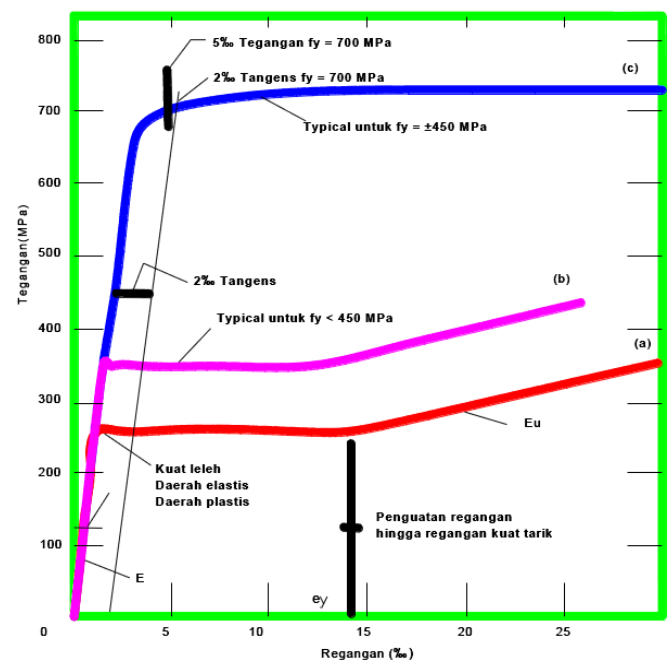

Gambar 2.1 Hubungan Tegangan Regangan Pada Daerah Lebih Rinci

(Mangkoesoebroto, 2007)

Jembatan gantung adalah jenis jembatan yang menggunakan tumpuan ketegangan kabel daripada tumpuan samping. Sebuah jembatan gantung biasanya memiliki kabel utama (kbel baja atau rantai yang lain) berlabuh di setiap ujung jembatan. Setiap beban yang diterapkan ke jembatan berubah menjadi ketegangan dalam kabel utama.

Pendukung untuk bangunan jembatan gantung perlu adanya

- Blok angkur

- Menara portal

- Dan girder lantai. 
Desain jembatan yang ingin saya tampilkan adalah jembatan sederhana di desa, desain ini untuk beban kendaraan yang tidak terlalu tinggi, mungkin dikarenakan volume lalulintas harian rata-rata nya tidak seperti kebutuhan di jalan nasional, atau bisa di sebut jalan arteri atau sekunder.

Kebutuhan untuk lalu lintas(lalin) jembatan ini hanya untuk kendaraan roda dua dan kendaraan roda empat dalam kategori minibus.

Jembatan ini tidak dapat banyak memikul beban, karena bangunan girder dan plat lantai nya dibangun dari plat $\mathrm{C}$ baja dan lantai kayu, jadi tidak bisa menerima beban seperti beban layaknya jalan arteri dan primer lainnya, pengaruh beban yang dipikul pun di tumpukan semua kepada kabel, jadi jembatan ini tidak membutuhkan pilar sehingga lebih ekonomis dalam membangun sebuah jembatan di daerah pelosok dan terpencil.

Dengan adanya nya jembatan ini sangat membantu dalam kemajuan transportasi dan ekonomi, dan bisa juga terjadi tarikan dan bangkitan.

Tarikan dan bangkitan sangat perlu, dengan adanya sarana dan prasarana jalan, sehingga sangat mempengaruhi kemajuan ekonomi di suatu wilayah lebih-lebih lagi di wilayah pedesaan, contoh terjadinya tarikan bangkitan yaitu menjadi tinggi nya harga tanah disuatu wilayah dan bisa mengundang penduduk untuk membangun rumah atau bangunan lainnya diwilayah tersebut atau perpindahan penduduk dari suatu tempat yang padat kepada tempat yang jarang penduduknya,sehingga terjadinya pergerakan dan perputaran ekonomi baru disuatu wilayah.

\subsection{Indetifikasi Perilaku Jembatan}

Mengidentifikasi/memperkirakan secara tepat penerapan desain geometric (alinemen horizontal dan vertical) dan melaksanakan pekerjaan ini dengan melakukan pengukuran-pengukuran secara khusus untuk lokasi-lokasi yang dianggap sulit untuk memastikan trase yang dipilih akan dapat memenuhi persyaratan geometric yang dibuktikan dengan sketsa horizontal dan penampang memanjang trase jembatan gantung.

Di dalam penarikan perkiraan desain alinement horizontal dan vertical harus sudah diperhitungkan dengan cermat sesuai dengan kebutuhan perencanaan untuk lokasi-lokasi galian dan timbunan, bangunan pelengkap jalan, gorong-gorong dan jembatan (oprit jembatan), persimpangan yang bisa terlihat dengan dibuatnya sketsa-sketsa serta tabelaris di lapangan dari identifikasi kondisi lapangan secara stasioning dari awal sampai dengan akhir proyek.

\subsection{Validasi}

Hasil analisis model elemen hingga yang sudah diolah akan dilakukan validasi model. Validasi model membandingkan hasil analisis model menggunakan SAP 2000 dengan hasil eksperimental 
dengan tingkat kesalahan validasi maksimal 10 persen dari analisis tersebut. Jika tingkat kesalahan validasi lebih dari 10 persen, maka perlu dilakukan pengecekan kembali terhadap input data ke program komputasi SAP 2000 Sedangkan validasi antara hasil analisis model menggunakan SAP 2000 dengan perhitungan manual adalah kurang dari 20 persen. Jika hasil tersebut telah tervalidasi semua, maka dapat digunakan mengambil kesimpulan dari model tersebut dan dilanjutkan dengan pembuatan model dengan variasi yang telah ditetapkan dalam batasan penelitian.

\subsection{Permodelan}
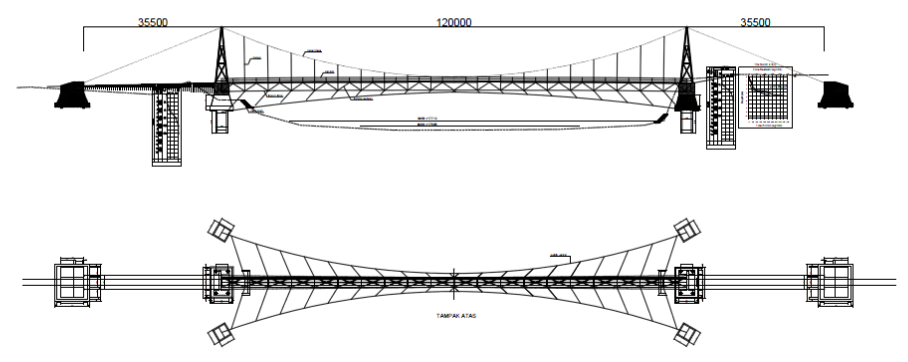

Gambar 2.2 Gambar Jembatan Gantung Existing

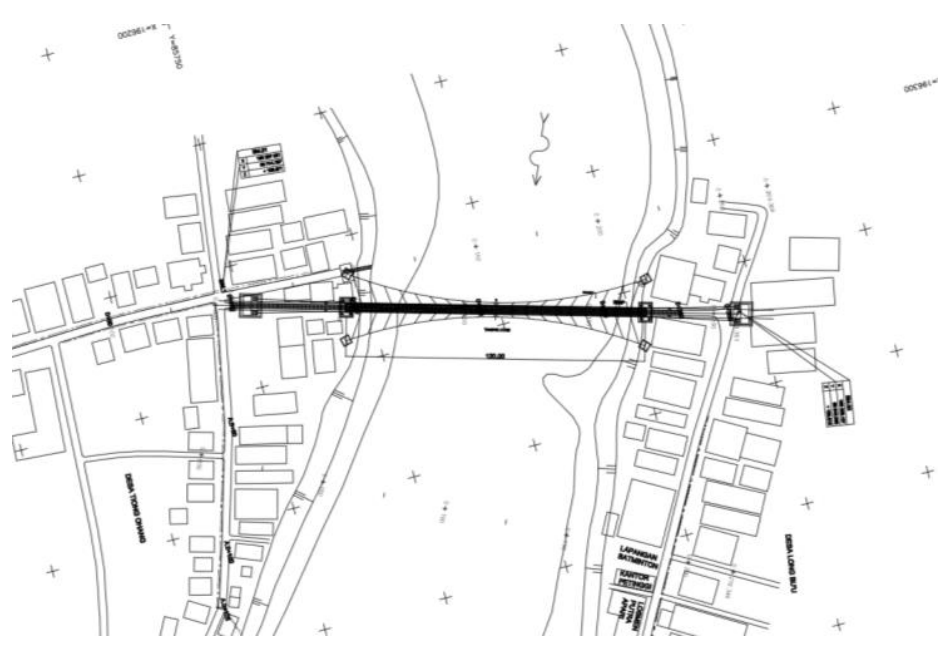

Gambar 2.3 Layout Jembatan Gantung Existing

Jembatan gantung dimodelkan dengan menggunakan analisis elemen hingga dengan SAP 2000 adalah dua jenis model penampang sama namun terjadi perubahan posisi blok angkur atau Fondasi pengaku kabel utama jembatan gantung, yaitu yaitu dengan desain awal berjarak 35,5 meter 
menjadi 24 meter.. Kurva gaya yang terjadi dengan analisis SAP 2000 dalam bentuk linier, hal ini bertujuan untuk mendapatkan devisiasi jumlah gaya yang terjadi.

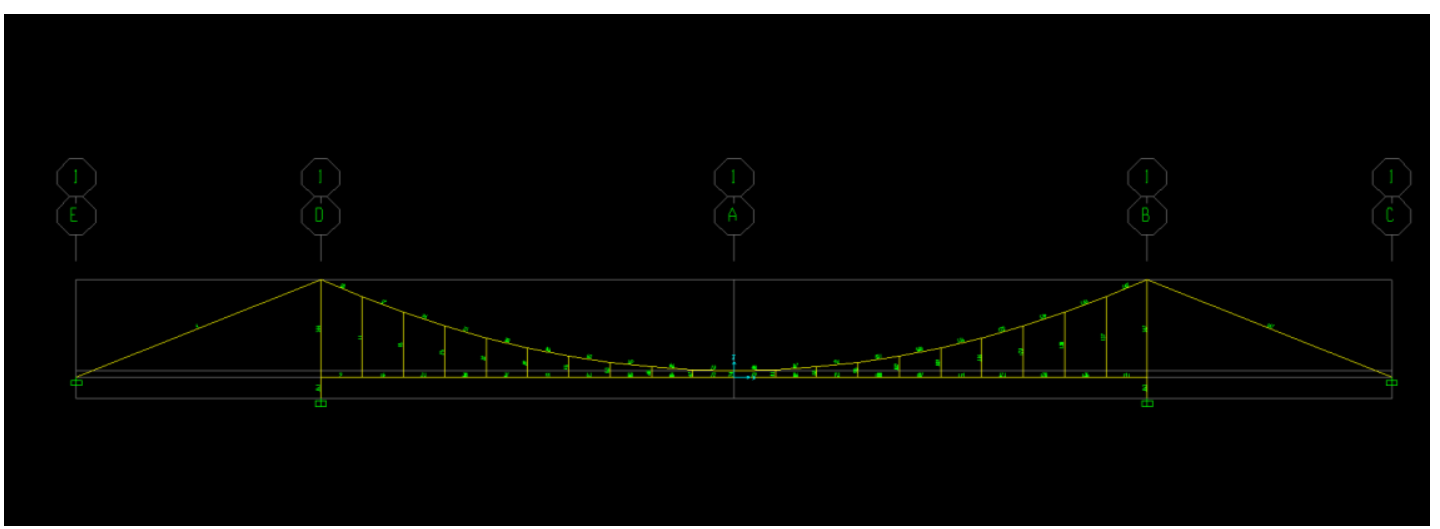

Gambar 2.4 Permodelan di SAP 2000

\section{HASIL EVALUASI}

Dari hasil permodelan dengan menggunakan program metode elemen hingga yaitu SAP 2000 di dapatkan hasil sebagaimana tabel di bawah ini:

Tabel 3.1. Gaya yang terjadi pada blok angkur

\begin{tabular}{|c|c|c|c|c|}
\hline Gaya yang terjadi & $\begin{array}{c}\text { Blok Angkur/ } \\
\text { Fondasi Pengaku }\end{array}$ & $\begin{array}{c}\text { Kolom Penyanggah/ } \\
\text { Menara Portal }\end{array}$ & $\begin{array}{c}\text { Kabel } \\
\text { Penyanggah }\end{array}$ & Satuan \\
\hline MOMEN 35,5M & 18.053 & 8.161 & 8.415 & Ton-M \\
\hline MOMEN 24M & 17.231 & 0.398 & 0.423 & Ton-M \\
\hline AXIAL 35,5M & 90.978 & 87.389 & 114.111 & Ton \\
\hline AXIAL 24M & 113.518 & 109.901 & 125.707 & Ton \\
\hline
\end{tabular}

\section{PERBANDINGAN NILAI MOMEN}

15

10

0 


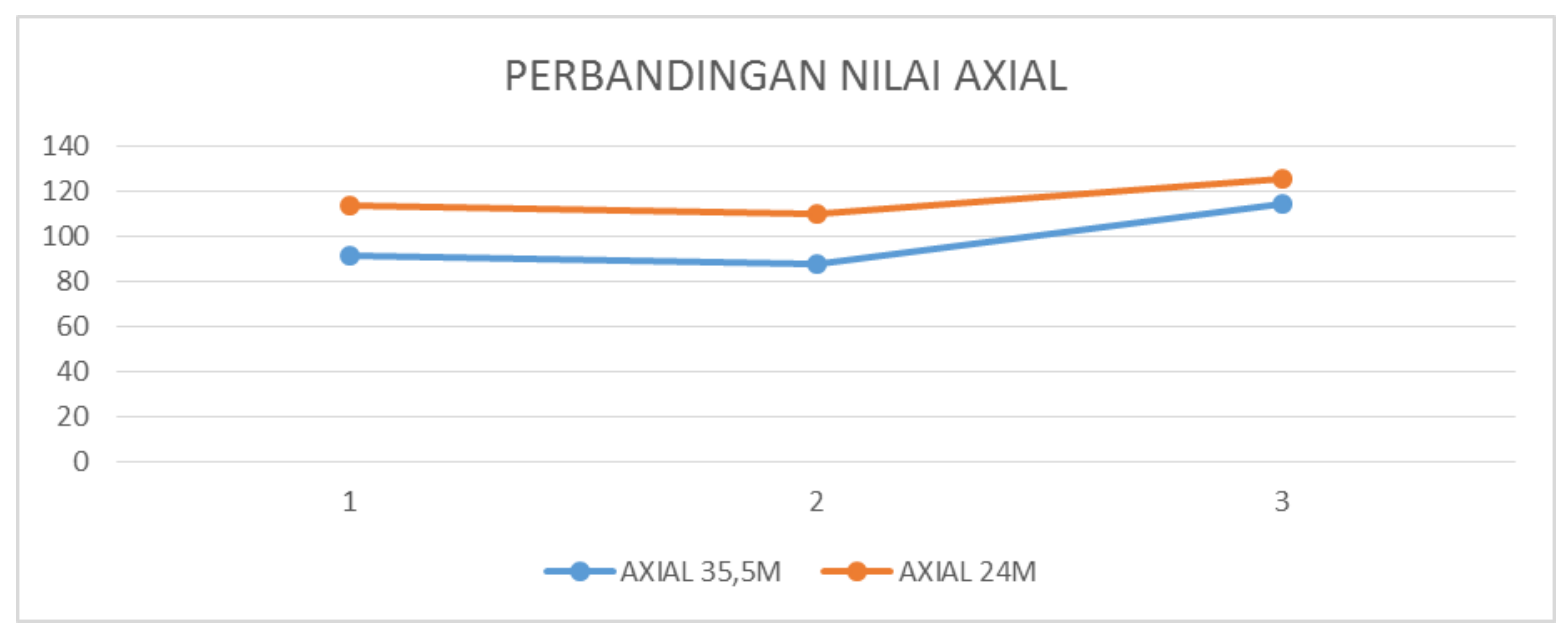

Gambar 3.2 Perbandingan Nilai Gaya Axial

Terlihat tren bahwa terjadi penurunan gaya momen yang terjadi pada kabel blok angkur dengan panjang 24 meter dan 35,5 meter di mana blok angkur terjadi penurunan nilai momen sebesar 4,55 persen, sedang menara portal terjadi penurunan nilai momen sebesar 95,12 persen sedang nilai gaya momen yang terjadi pada kabel utama terjadi penurunan sebesar 94,97 persen, terlihat pada tabel di bawah ini:

Tabel: 3.2. Persentase Perubahan Nilai Momen Bentang Panjang Pada Blok Angkur

\begin{tabular}{|c|c|c|c|c|}
\hline Gaya yang terjadi & $\begin{array}{c}\text { Blok Angkur/ } \\
\text { Fondasi Pengaku }\end{array}$ & $\begin{array}{c}\text { Kolom Penyanggah/ } \\
\text { Menara Portal }\end{array}$ & $\begin{array}{c}\text { Kabel } \\
\text { Penyanggah }\end{array}$ & Satuan \\
\hline MOMEN 35,5M & 18.053 & 8.161 & 8.415 & Ton-M \\
\hline MOMEN 24M & 17.231 & 0.398 & 0.423 & Ton-M \\
\hline Nilai Persentase & $\mathbf{4 . 5 5}$ & $\mathbf{9 5 . 1 2}$ & $\mathbf{9 4 . 9 7}$ & $\%$ \\
\hline
\end{tabular}

Terlihat tren bahwa terjadi kenaikan gaya axial yang terjadi pada kabel blok angkur dengan panjang 24 meter dan 35,5 meter di mana blok angkur terjadi penurunan nilai momen sebesar 19.86 persen, sedang menara portal terjadi penurunan nilai momen sebesar 20.48 persen sedang nilai gaya momen yang terjadi pada kabel utama terjadi penurunan sebesar 9.22 persen, terlihat pada tabel di bawah ini: 
Tabel: 3.2. Persentase Perubahan Nilai Gaya Axial Bentang Panjang Pada Blok Angkur

\begin{tabular}{|c|c|c|c|c|}
\hline Gaya yang terjadi & $\begin{array}{c}\text { Blok Angkur/ } \\
\text { Fondasi Pengaku }\end{array}$ & $\begin{array}{c}\text { Kolom Penyanggah/ } \\
\text { Menara Portal }\end{array}$ & $\begin{array}{c}\text { Kabel } \\
\text { Penyanggah }\end{array}$ & Satuan \\
\hline AXIAL 35,5M & 90.978 & 87.389 & 114.111 & Ton \\
\hline AXIAL 24M & 113.518 & 109.901 & 125.707 & Ton \\
\hline Nilai Persentase & $\mathbf{1 9 . 8 6}$ & $\mathbf{2 0 . 4 8}$ & $\mathbf{9 . 2 2}$ & $\%$ \\
\hline
\end{tabular}

\section{KESIMPULAN}

Berdasarkan uraian mengenai kerusakan-kerusakan yang terdapat pada bangunan studi kasus serta pelaksanaan perbaikan dan perkuatan yang telah dilakukan, dapat diambil beberapa kesimpulan:

1. Terdapat perubahan signifikan yang terjadi pada momen dan gaya axial yang terjadi jika dilakukan perubahan jarak bentang pada blok angkur jembatan gantung

2. Momen yang terjadi cenderung berubah lebih kecil jika jarak blok angkur diperpendek

3. Namun gaya axial cenderung dominan bertambah jika jarak blok angkur diperkecil.

\section{DAFTAR KEPUSTAKAAN}

AISC, American Institute Steel Construction, Manual of Steel Construction, eighth edition, Icc.400 North Michigan Avenue Chicago, Illinois 60611

Barus S, Analisis Baut Mutu Tinggi Serta Aplikasinya Pada Hubungan Balok- Kolom Dep.Teknik Sipil, 2008

PPBBI, Peraturan Perencanaan Bangunan Baja Indonesia, Yayasan Lembaga Penyelidikan Masalah Bangunan Bandung

Badan Standarisasi Nasional. 2005. Standar Pembebanan Jembatan. RSNI T-02-2005. Jakarta

Bridge Management System. Peraturan Perencanaan Teknik Jembatan. BMS 1992.

Departemen PU Bina Marga

Badan Standarisasi Nasional. 2005. Perencanaan Struktur Baja Untuk Jembatan. RSNI T-032005. Jakarta

Badan Standarisasi Nasional. 2004. Perencanaan Struktur Beton Untuk Jembatan. RSNI T-122004. Jakarta 
Badan Standarisasi Nasional. 2008. Standar Perencanaan Gempa untuk Jembatan. SNI 28332008 . Jakarta

Surat Edaran Menteri Pekerjaan Umum dan Perumahan Rakyat.

Pedoman Perencanaan Teknis Jembatan Beruji Kabel. 08/SE/M/2015. Jakarta

Penyusunan Study Kelayakan Rencana Pembangunan Jembatan II Sungai Indragiri Tembilahan Prasetyo, Wahyu. 2013. Perencanaan Ulang Jembatan Sungai Berantas

pada Jalan Tol Kertosono- Mojokerto dengan Metode Cable Stayed. Jember

Troitsky, M.S. 1977. Cable Stayed Bridges: Theory and Design. London: Crosby Lockwood Staples.

Walther, R. 1999. Cable Stayed Bridges.London: Thomas Telford. Podolny \& Scalzi. 1976. Construction and Design of Cable Stayed

Bridges. New York: Wiley \& Sons Inc. Yuskar, L. \& Andi, I. 2005. Kajian Sambungan antara Pilar dan Kabel.

Taufik S., Numerical Modelling of Semi-rigid Connection with High Strength Steel, Study of Civil Engineering and Architecture (SCEA) Volume 2 Issue 2, 2013

Taufik S. and Xiao R.Y., Predicted Behavior Of Partially Restrained Connection With Cold Formed High Strength Steel By 3D Finite Element Modelling, Advanced Materials Research, Trans Tech Publications, Switzerland, AMR 250-253. 2011

Taufik S., Behaviour Of Bolted Connection With High Strength And Stainless Steel, Phd Thesis, Swansea University UK, 2008

Taufik S. and Xiao R.Y., Computing Frame Analisys of Partially Restrained Connection with Starin Softening Effect, Proceedings of The Eleventh International Conference on Civil, Structural and Environmental Engineering Computing, B.H.V. Topping, G. Montero and R. Montenegro, (Eds), Civil-Comp Press, Stirlingshire, UK, paper 153, 2007 